OPEN ACCESS

Edited by:

Yih-Kuen Jan,

University of Illinois

at Urbana-Champaign, United States

Reviewed by:

Fu-Lien Wu,

University of Illinois at Urbana-Champaign, United States

Fuyuan Liao,

Xi'an Technological University, China

${ }^{*}$ Correspondence:

Jose A. Adams tony.adams@msmc.com

tony@msmc.com

tThese authors have contributed equally to this work

${ }^{\ddagger}$ Deceased

Specialty section

This article was submitted to Clinical and Translational Physiology, a section of the journal

Frontiers in Physiology

Received: 06 December 2020

Accepted: 29 January 2021

Published: 23 February 2021

Citation:

Adams JA, Uryash A, Lopez JR and Sackner MA (2021) The Endothelium as a Therapeutic Target in Diabetes: A Narrative Review and Perspective.

Front. Physiol. 12:638491. doi: 10.3389/fphys.2021.638491

\section{The Endothelium as a Therapeutic Target in Diabetes: A Narrative Review and Perspective}

\author{
Jose A. Adams ${ }^{1 *}$, Arkady Uryash ${ }^{1+}$, Jose R. Lopez ${ }^{2 \dagger}$ and Marvin A. Sackner ${ }^{3+\neq}$ \\ ${ }^{1}$ Division of Neonatology, Mount Sinai Medical Center, Miami Beach, FL, United States, ${ }^{2}$ Department of Research, Mount \\ Sinai Medical Center, Miami Beach, FL, United States, ${ }^{3}$ Department of Medicine, Mount Sinai Medical Center, Miami Beach, \\ FL, United States
}

Diabetes has reached worldwide epidemic proportions, and threatens to be a significant economic burden to both patients and healthcare systems, and an important driver of cardiovascular mortality and morbidity. Improvement in lifestyle interventions (which includes increase in physical activity via exercise) can reduce diabetes and cardiovascular disease mortality and morbidity. Encouraging a population to increase physical activity and exercise is not a simple feat particularly in individuals with comorbidities (obesity, heart disease, stroke, peripheral vascular disease, and those with cognitive and physical limitations). Translation of the physiological benefits of exercise within that vulnerable population would be an important step for improving physical activity goals and a stopgap measure to exercise. In large part many of the beneficial effects of exercise are due to the introduction of pulsatile shear stress (PSS) to the vascular endothelium. PSS is a well-known stimulus for endothelial homeostasis, and induction of a myriad of pathways which include vasoreactivity, paracrine/endocrine function, fibrinolysis, inflammation, barrier function, and vessel growth and formation. The endothelial cell mediates the balance between vasoconstriction and relaxation via the major vasodilator endothelial derived nitric oxide (eNO). eNO is critical for vasorelaxation, increasing blood flow, and an important signaling molecule that downregulates the inflammatory cascade. A salient feature of diabetes, is endothelial dysfunction which is characterized by a reduction of the bioavailability of vasodilators, particularly nitric oxide (NO). Cellular derangements in diabetes are also related to dysregulation in $\mathrm{Ca}^{2+}$ handling with increased intracellular $\mathrm{Ca}^{2+}$ overload, and oxidative stress. PSS increases eNO bioavailability, reduces inflammatory phenotype, decreases intracellular $\mathrm{Ca}^{2+}$ overload, and increases antioxidant capacity. This narrative review and perspective will outline four methods to non-invasively increase PSS; Exercise (the prototype for increasing PSS), Enhanced External Counterpulsation (EECP), Whole Body Vibration (WBV), Passive Simulated Jogging and its predicate device Whole Body Periodic Acceleration, and will discuss current knowledge on their use in diabetes.

Keywords: pulsatile shear stress, whole body periodic acceleration, enhanced external counter pulsation, whole body vibration, passive jogging device, exercise, diabetes, nitric oxide 


\section{INTRODUCTION}

Diabetes is a worldwide epidemic, with a global prevalence of over 425 million. Diabetes accounts for nearly $9.4 \%$ of the United States population with an estimated cost of over $\$ 300$ billion annually (Willey et al., 2018). Globally diabetes will have an economic burden of over $\$ 2.1$ trillion by 2030 (Bommer et al., 2018). Diabetes is a public health threat and one of the most important risk factors for cardiovascular disease. Type 2 diabetes (T2D), accounts for $90 \%$ of all persons with diabetes (American Diabetes, 2020). An absolute or progressive loss of adequate insulin secretion and insulin resistance, leads to the cardinal manifestation of diabetes which is hyperglycemia. Hyperglycemia, leads to a host of cellular derangements which induce free radial generation leading to oxidative stress (Yaribeygi et al., 2019), endothelial dysfunction (Meza et al., 2019; Tran et al., 2020), and cardiomyocyte dysfunction leading to heart failure (Singh et al., 2018; Nakamura and Sadoshima, 2020). Further, hyperglycemia impacts the immune system with suppressed cytokine production, defects in leukocyte recruitment, and dysfunction in neutrophil, macrophages, and natural killer cell (Berbudi et al., 2020). Key determinants of the effects of diabetes on both cardiomyocytes and vascular endothelial cells involve decrease in nitric oxide (NO) bioavailability, increase reactive oxygen species (ROS), and inflammation (Goligorsky, 2017; Filardi et al., 2019; Joubert et al., 2019; Trigglea et al., 2020) as well as deranged calcium homeostasis (Murtaza et al., 2019). It would be overly simplistic to only recognize hyperglycemia as the culprit in diabetes, but insulin resistance also induces signaling pathways which are involved in the micro and macro vascular pathologies which are seen in diabetes (Petersen and Shulman, 2018).

A salient feature of diabetes, is endothelial dysfunction. Endothelial dysfunction is characterized by a reduction of the bioavailability of vasodilators, particularly nitric oxide (NO), and/or an increase in endothelium-derived contracting factors (Hadi et al., 2005; Sena et al., 2013; Cyr et al., 2020). The resulting imbalance leads to an impairment of endotheliumdependent vasodilation, which is the functional characteristic of endothelial dysfunction. Endothelial dysfunction is the hallmark of various cardiovascular diseases including, heart failure, the precursor to atherosclerosis, early stages of Alzheimer disease, and micro and macrovascular disease (Jia et al., 2018; Takeda et al., 2020). Additionally, cellular derangements in diabetes are related to dysregulation in $\mathrm{Ca}^{2+}$ handling particularly in cardiomyocytes. The latter mainly occurs due to defects in sarcolemmal $\mathrm{Na}^{+} / \mathrm{K}^{+}$ATPase, $\mathrm{Na}^{+} / \mathrm{Ca} 2^{+}$exchange, $\mathrm{Na}^{+} / \mathrm{H}^{+}$ exchange, $\mathrm{Ca}^{2+}$-channels and $\mathrm{Ca}^{2+}$-pump activities as well as changes in sarcoplasmic reticular $\mathrm{Ca}^{2+}$-uptake and $\mathrm{Ca}^{2+}$-release processes. These alterations lead to intracellular $\mathrm{Ca}^{2+}$ overload (Zarain-Herzberg et al., 2014; Singh et al., 2018).

To understand the concept of utilizing pulsatile shear stress (PSS) as a therapeutic intervention one must understand the endothelium. The endothelium is a monolayer of endothelial cells (EC) which covers the luminal surface of arteries, veins, capillaries, and the heart. The EC surface area covers $3000-6000 \mathrm{~m}^{2}$ of the human body. The EC is heterogeneous, numerous in location and vast in mediators (Davies, 1995;
Aird, 2003; Ohura et al., 2003; Bryan et al., 2014; Firasat et al., 2014; He et al., 2020), and adaptive as to its response to stimulus (Resnick et al., 2003; Chien, 2007; Himburg et al., 2007; Zhang and Friedman, 2012, 2013). The EC is vital as both a transducer of a multitude of mechanical and biochemical signals, as well as an effector cell. The mechanical sensing capabilities of EC are governed by physical forces (tangential, radial, axial) and local blood flow patterns (Gordon et al., 2020; Roux et al., 2020). Blood flow produces mechanical frictional forces which produce endothelial shear stress, in addition with each contraction of the heart a pulse is added to the circulation due to the mechanical contraction of the heart producing PSS, pulsatile shear stress promotes EC homeostasis and vascular health (Kruger-Genge et al., 2019; Gordon et al., 2020). In addition to frequency of pulsatility, flow patterns within the vasculature are also important. Whereas laminar shear stress (tangential to the surface of the blood vessel) produces a cytoprotective EC phenotype (non-atherogenic, non-inflammatory), oscillatory shear (OS, as seen in areas of vascular stenosis or bifurcation) and low shear stress have been shown to be inflammatory and atherogenic (Qiu and Tarbell, 2000; Kadohama et al., 2007; Laughlin et al., 2008; Zhou et al., 2014; Ajami et al., 2017; Wang et al., 2019; Souilhol et al., 2020). Endothelial cells are interconnected by cellular junctions that confer selective permeability. The EC's strategic location to sense and respond to both hemodynamic changes as well as circulating biochemical signals, makes it a formidable regulator of the human body's general homeostasis. The input of the EC thus relates to both mechanical (shear stress) as a mechanosensor and biochemical signals as a chemosensor (Campinho et al., 2020; He et al., 2020). The output of the EC is involved in a myriad of pathways, which includes vasoreactivity, paracrine/endocrine function coagulation and blood fluidity, inflammation, barrier function, vessel growth, and formation (vasculogenesis, angiogenesis, arteriogenesis) (Trigglea et al., 2020).

The endothelium mediates the balance between vasoconstriction/relaxation by secreting mediators, such as endothelin-1 and thromboxane-A2 (vasoconstriction) and nitric oxide (NO), prostacyclin, and endotheliumderived hyperpolarizing factor (EDHF) (vasodilatation). This summary will focus our attention on the most important vasoactive/signaling molecule endothelial derived nitric oxide (eNO), and antioxidants. Nitric Oxide (NO) is a gas which is important in signal transduction, protein S-Nitrosylation, and critical for vasodilation (Forstermann and Sessa, 2012; Duran et al., 2013; Ghimire et al., 2017; Farah et al., 2018). NO is produced by oxidation of L-arginine to L-citrulline utilizing the enzyme nitric oxide synthase (NOS) and tetrahydrobiopterin $(\mathrm{BH} 4)$ as cofactor to produce NO. There are three nitric oxide synthases; (a) Endothelial derived nitric oxide synthase (eNOS) produced in most tissues but primarily in the endothelium. eNOS is constitutively expressed and calcium dependent. eNOS produces nanomolar amounts of NO. (b) Inducible nitric oxide synthase (iNOS), which is not constitutively expressed. iNOS produces large quantities of NO, usually produced by macrophages, and inflammatory cells, and (c) Neuronal nitric oxide synthase (nNOS) which is found mostly in both 
neuronal and cardiovascular tissue, has a role in neuronal signal transduction and chronotropicity of the heart (Ziolo et al., 2008; Forstermann and Sessa, 2012). eNO is an important molecule, which is produced in response to pulsatile shear stress. In classic and elegant experiments performed by Hutchenson et al., they found that NO [previously called endothelium derived relaxing factor (EDRF)] is produced by endothelial cells as a function of pulsatility with optimum frequency of pulsation of 2-8 Hz (120-480 cpm) (Hutcheson and Griffith, 1991). The direct response of eNOS activation and $\mathrm{NO}$ production to PSS in these experiments and others, have clearly shown that PSS is important for endothelial homeostasis. eNO is critical for vasorelaxation, increasing blood flow, and an important signaling molecule that downregulates the inflammatory cascade (Albrecht et al., 2003; Cirino et al., 2003; Kolluru et al., 2010; Forstermann and Sessa, 2012). The concept of modulating the endothelium using PSS via non-invasive methods, is thus an attractive method to modify or prevent various chronic diseases including diabetes. The prototype of such a model is exercise. Unfortunately, comorbidities (obesity, heart failure, peripheral vascular disease, stroke, and physical or cognitive limitations) which coexist in the diabetic population and those at risk, make exercise difficult or impossible. Simple methods to induce PSS are highly desirable to maintain endothelial homeostasis, promote eNO for cell signaling and combat downstream effects of diabetes at the cellular level. This review will first focus on exercise, the prototype for non-invasive methods for PSS, and discuss Enhanced External Counterpulsation (EECP), Whole Body Vibration (WBV), and Passive Simulated Jogging Device (JD) and its predicate device Whole Body Periodic Acceleration (WBPA) within the context of their beneficial effects on diabetes.

\section{INTERVENTIONS TO ACHIEVE PULSATILE SHEAR STRESS AND SEARCH METHODS}

Pulsatile Shear Stress, occurs naturally in the human body. Each contraction of the heart adds pulsations to the circulation, producing a frequency of pulsatility of 1 to $2 \mathrm{~Hz}$ and additional pulsations to the circulation beyond this frequency increases eNO bioavailability (Hutcheson and Griffith, 1991; Stefano et al., 2001).

This review will focus on four non-pharmacologic methods for sustained shear stress, which increase pulsatile shear stress to the vascular endothelium and have been shown to confer a protective role in diabetes and other diseases; Exercise, EECP, WBV, and Whole Body Periodic Acceleration (WBPA/pGz), or Passive Jogging Device (JD) Figure 1.

In addition to the above interventions a literature search was performed using PubMed and EMBASE Databases. The first search involved key terms; Pulsatile Shear Stress or Shear Stress (457 articles), two additional methods were identified. Individual Shear Rate Therapy (ISRT, a method which is similar to EECP) and Pulsed High Intensity Ultrasound (a method not used as therapy in diabetes). The following key terms were then used; (a) diabetes or diabetes mellitus, or diabetic, and exercise or exercises or exercise therapy. (b) enhanced external counterpulsation or counterpulsation, or external counterpulsation, and diabetes or diabetes mellitus, or diabetic (c) whole body vibration or body vibration, or human body vibration and diabetes or diabetes mellitus, (d) passive simulated jogging or passive jogging or simulated jogging and diabetes or diabetes mellitus, or diabetic (e) whole body periodic acceleration or periodic acceleration and diabetes or diabetes mellitus, or diabetic. The search was limited to randomized controlled trials, review articles, or meta-analyses, with studies limited to those in English with human participants. Titles and abstracts were reviewed for relevant information with regards to the aforementioned sustained pulsatile shear stress interventions in relation to diabetes. Search dates January 1990 to November 2020.

\section{EXERCISE}

\section{Exercise for Pulsatile Shear Stress}

Exercise is the prototype of a non-invasive method to increase pulsatile shear stress. Shear stress (SS) and/or circumferential wall stress (stretch) are the primary signals produced by exercise. SS levels in the arteries of humans during exercise are in the range that produces beneficial changes in endothelial phenotype (Laughlin et al., 2008; Zhang and Friedman, 2013; Bender and Laughlin, 2015). The mechanisms responsible for the effects of exercise on the endothelial cell and vasculature are both primary and secondary in nature, and are in addition to benefits produced by changes in cardiovascular risk factors such as lipid profiles and blood pressure which occur in concert with the direct effects of arterial shear stress and mechanotransduction (Green and Smith, 2018). Exercise exerts direct effects on the vasculature via the impact of repetitive exposure to hemodynamic stimuli, such as shear stress and transmural pressure (Green et al., 2017; Wang et al., 2019).

Pulsatility, as well as shear stress, induce anti-inflammatory, and an atheroprotective phenotype in endothelial cells. Lifestyle modifications include both diet and exercise and have remained paramount in the management of both type 1 and type 2 diabetes. The primary goal of exercise in diabetes is to improve overall cardiovascular health, improve insulin sensitivity, and modify endothelial dysfunction produced by diabetes. Some of the additional features of exercise which benefit the management of diabetes include the reduction of oxidative stress. Pulsatile shear stress (PSS) is produced by exercise, and in particular running, jogging, or walking. As the individual walks or runs, additional pulses are added to the circulation from each step to the already existing cardiac pulsations. Thus, the cadence of walking or running provide additional pulsatility. Step frequency for both males and females recreational runners has been estimated between 163 and 169 steps per min (Clermont et al., 2019). This frequency is in addition to a baseline cardiac pulsatility of 60-100 beats/min, and therefore generates total pulsation close to $220-240$ beats per $\min (3-4 \mathrm{~Hz})$. Since the running cadence is not timed to the cardiac cycle one can expect frequencies in the range of $80-250$ (1.3 to $4 \mathrm{~Hz}$ ). It is not the intent of this narrative review to focus or discuss the various exercise strategies including 
A

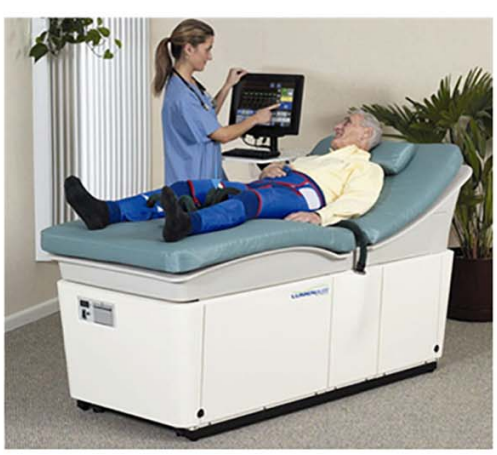

C

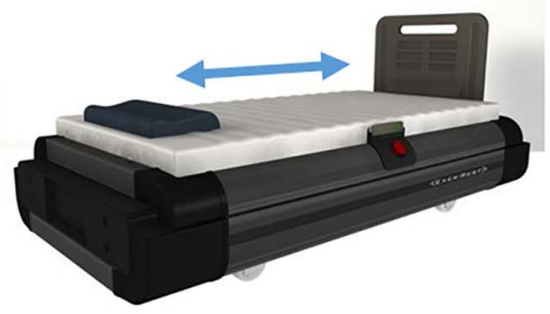

B

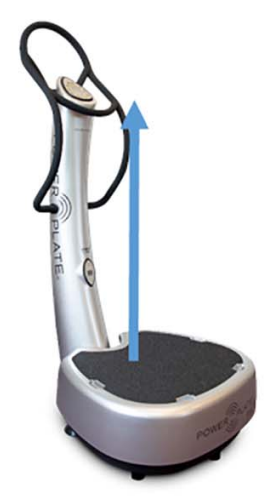

D



FIGURE 1 | Devices which produce sustained pulsatile shear stress. Devices which produce sustained pulsatile shear stress (PSS). (A) Enhanced External Counter Pulsation (EECP). External synchronized compression of the lower extremities via bladder like attachments on the lower extremities, the compressions are timed to diastole. Picture is The Lumenair ${ }^{T M}$ System EECP ${ }^{\circledR}$ both are registered trademarks of VasoMedical, Inc. (Courtesy of VasoMedical, Plainview, NY, United States. (B) Whole Body Vibration (WBV), provides vertical vibration, with the vector of movement in the foot to head direction (+ Gz). The pictured device is Power Plate ${ }^{\circledR}$ my5 ${ }^{\mathrm{TM}}$ (Performance Health Systems, LLC, Northbrook, IL, United States). (C) Whole Body Periodic Acceleration (WBPA) moves the supine body in a head to foot sinusoidal motion ( $\pm \mathrm{Gz}$ ). The pictured device is WBPA from Non-invasive Monitoring System (NIMS, Miami, FL, United States). (D) Passive Simulated Jogging Device (JD) is a passive motorized device which produces alternating movement of the foot simulating jogging introducing pulsations to the body. The device can be used in the seated or supine posture. The pictured device is the Gentle Jogger ${ }^{\circledR}$ (Sackner Wellness Products, Miami, FL, United States). Blue arrows represent the acceleration motion of each device.

resistance training or interval training which have been shown to produce beneficial effects on cardiovascular health, various excellent reviews have been published on this aspect (Kojda and Hambrecht, 2005; Ploughman, 2008; Wilson et al., 2016; Adams et al., 2017; Trigiani and Hamel, 2017; Fletcher et al., 2018; Yanai et al., 2018; Pinckard et al., 2019; Trinity and Richardson, 2019; Brown et al., 2020).

\section{Exercise and Diabetes}

Under normal conditions glucose transporter-4 (GLUT-4) an intracellular protein is translocated to the cell membrane in response to insulin where it facilitates glucose uptake and utilization. In diabetes expression and function of GLUT-4 are compromised, leading to a reduction in glucose transport. Exercise increases GLUT-4 expression and glucose transport (Richter and Hargreaves, 2013). Additionally, exercise increases GLUT-4 translocation in healthy and diabetic models (Dohm, 2002; Henriksen, 2002; Ito et al., 2006). Exercise also induces pancreatic $\beta$ cells to increase insulin secretion activating insulin signaling pathway, upregulating GLUT-4 expression and enhancing intracellular energy metabolism (Stanford and Goodyear, 2014). Dysregulation of intracellular $\left(\mathrm{Ca}^{2+}\right)$ homeostasis is another marker of diabetes, particularly in cardiomyocytes. Exercise improves the expression and activity of the $\mathrm{Ca}^{2+}$-ATPase (SERCA2a), and regulates $\mathrm{Ca}^{2+}$ levels via $\mathrm{Ca}^{2+}$ calmodulin- dependent protein kinase phosphorylation (Sturek, 2011; Guerrero-Hernandez and Verkhratsky, 2014). Hyperglycemia is also associated with chronic inflammation and oxidative stress. Hyperglycemia enhances the production of oxygen free radicals and apoptosis. Exercise reduces the production of ROS, and reduces oxidative stress damage, additionally exercise upregulates the expression and function of anti-oxidants enzymes superoxide dismutase, glutathione peroxidase and catalase (Seo et al., 2019), and "exerkines" (Yu et al., 2017). As a result of the above, exercise in diabetic patients; reduces overall cardiovascular disease burden, improves endothelial function, improves indices of cardiac dysfunction, reduces overall hyperglycemic time and reduces the long term index of poor glucose control (glycated hemoglobin, HbA1C) (Seo et al., 2019). Exercise is simple intervention, which reduces cardiovascular morbidity and mortality and positively correlates with beneficial health outcomes as they pertain to diabetes and other chronic illnesses. Exercise requires subject cooperation and comorbidities previously mentioned in the population with or at risk for diabetes may preclude patients from engaging and remaining on an exercise program. The following methods 
provide a stop-gap measure and potential alternatives for harnessing the beneficial effects of PSS.

\section{ENHANCED EXTERNAL COUNTERPULSATION}

\section{Enhance External Counterpulsation (EECP) for Pulsatile Shear Stress}

Enhanced external counterpulsation (EECP) is a non-invasive therapy which has its origin in the 1960s in a study by Kantrowitz (1953) related to an invasive mechanical delay of the aortic pressure pulse in an animal model, and by 1976 the device matured to its present form (Zheng et al., 1984). EECP involves pneumatic inflation of three pairs of cuffs, compressing the calves, thighs and buttocks in a sequential distal to proximal manner timed to early diastole followed by deflation before systole (Raza et al., 2017). The frequency of additional pulsations induced by EECP is a function of the subject's intrinsic heart rate, since for every single diastole there is a corresponding inflation. EECP effectively doubles the heart rate pulsatility (120-200 beats/min or 2-3.3 Hz). In addition to pulsatile shear stress, EECP imparts circumferential stretch, and analysis of flow patterns under EECP, have also shown a less oscillatory flow (which is associated with endothelial dysfunction and proatherogenic phenotype) (Li et al., 2019). Original indications for EECP where related to angina due to coronary artery disease (CAD). The beneficial effects of EECP have expanded to peripheral artery disease, diabetes, erectile dysfunction, and possibly Alzheimer's disease. Similar to exercise, EECP adds additional pulsations to the endothelium, which have been shown to induce production of nitric oxide (Akhtar et al., 2006), improve flow mediated vasodilation (FMD) endothelial function (Shechter et al., 2003; Braith et al., 2010), attenuate proinflammatory signaling pathways (Zhang et al., 2010; Martin and Braith, 2012) and improve quality of life (Jan et al., 2020) amongst others. The mechanisms for the effects produced by EECP appear to have both a central hemodynamic component with decreased afterload, increased coronary blood flow, and a peripheral effect (passive exercise) (Braith et al., 2012; Raza et al., 2017). In addition to the aforementioned, EECP also improves the oscillatory flow pattern in stenosed coronary arteries (Xu et al., 2020). The EECP device has a large footprint $\left(1,861,800 \mathrm{~cm}^{3}\right)$ with an approximate reported cost above $\$ 100,000$ ( $£ 90,000$ ) (McKenna et al., 2010). EECP requires the subject to travel to a specific center for use of the device, and to receive technical assistance to operate. Thus, EECP is primarily reserved for medical clinics and would most likely not have a role in the day to day therapeutic management for diabetes. Guidelines for consideration and potential risks and requirements have been published by Lin et al. (2020).

\section{Enhanced External Counterpulsation and Diabetes}

Enhanced External Counterpulsation has been used in subjects with abnormal glucose tolerance. Martin et al. showed improved markers of glucose tolerance including markers of improved insulin sensitivity after 7 weeks of treatment (five one hour session per week) (Martin and Braith, 2012; Martin et al., 2012, 2014). These changes are attributed to improve NO bioavailability and NO mediated glucose uptake (Martin et al., 2012). Sardina et al. found that EECP significantly decreases fasting plasma glucose, post-prandial glucose at $120 \mathrm{~min}$, and HgA1C in patients with T2D (Sardina et al., 2016a). In a longer term study in the same population they found decreased advanced glycation products (AGE) and receptors of advanced glycation products (RAGE) up to 6 months (Sardina et al., 2016b). These findings support a beneficial effect of EECP in the management of diabetes. These data support the hypothesis that PSS has therapeutic potential in the management of diabetes. Unfortunately, due to the need for supervised use, nonportability and cost EECP it cannot be done at home on daily basis as a routine therapeutic strategy.

\section{WHOLE BODY VIBRATION}

\section{Whole Body Vibration (WBV) for Pulsatile Shear Stress}

Whole body vibrations (WBV) are mechanical oscillations of any frequency which are transferred to the human body. The early physiological effects of body vibration where described by a Swedish gymnast, physician, and inventor Gustav Zander (1835-1920) and almost simultaneously Jean-Martin Charcot (1825-1893) in 1892 described the use of the "vibratory chair" in the treatment of various neurological diseases including Parkinson's (Goetz, 2009). In 1895, Dr. John Harvey Kellogg (the inventor of Kellogg's Corn Flakes) was the next inventor to utilize vibration technology for health and wellness, he patented the "Kellogg Chair" (Kellogg, 1908). In the 1960 the Russian space program used WBV as a way to simulate weight bearing loads for their cosmonauts while training and rehabilitation before, during, and after outer space missions. Parallel to the latter, scientific literature in the United States began describing the effects of WBV on central hemodynamic changes, ventilation, and behavioral effects (Hoover et al., 1961; Young et al., 1965; Shoenberger, 1972).

The mechanical oscillations for WBV are performed using a platform which moves in either the linear/vertical direction (up and down) or the pivotal/oscillatory (see-saw) motion of the body (Cardinale and Wakeling, 2005; Rittweger, 2010). The subjects are either standing (with various degrees of knee flexion) or in seated postures. The range of frequencies reported for WBV are 720 to $3,600 \mathrm{cpm}(12-60 \mathrm{~Hz})$ and displacements from $<1$ to $10 \mathrm{~mm}$ with $\mathrm{Gz}+1.5 \mathrm{mt} / \mathrm{sec}^{2}$. Frequencies below $10 \mathrm{~Hz}$ with a accelerations of $\mathrm{Gz}+1.5 \mathrm{mt} / \mathrm{sec}^{2}$ and higher have been shown to induce significant discomfort profiles (Zhou and Griffin, 2014; Huang and Zhang, 2019). There are a wide variety of protocols used with regards to frequencies, amplitudes, and exposure time, depending on the studied condition, additionally the great majority of studies exploring the effects of WBV utilize a structured exercise performed on the WBV platform. WBV has evolved primarily as sports training adjunct in sports medicine, 
as a method to improve muscle power. The effects of WBV have been summarized in systematic reviews in terms of outcomes for specific populations such as; improvements in bone mineral density in post-menopausal women (Robinson et al., 2016), leg muscle strength and balance improvement in elderly, balance and gait in patients with Parkinson's disease multiple sclerosis, stroke, improved balance and gait speed in the elderly, and walking performance following stroke (Fischer et al., 2019) improved functional exercise capacity and quality of life in chronic obstructive pulmonary disease, improved muscle strength bone mineralization and balance in children with Down's syndrome (Saquetto et al., 2018). WBV increases skin blood flow (Johnson et al., 2014; Robbins et al., 2014; Games et al., 2015), and improves endothelial function in an elderly population (Aoyama et al., 2019). Non-athletic commercial claims of weight loss are refuted by systematic reviews which failed to show change in lean body mass in obese subjects (Zago et al., 2018). The approximate cost of WBV platforms ranges from $\$ 1,000$ to $\$ 13,000$.

\section{Whole Body Vibration and Diabetes}

In a diabetic animal model (leptin-deficient $\mathrm{db} / \mathrm{db}$ mice) 12 weeks [ $1 \mathrm{~h}$ per day protocol $(f=45 \mathrm{~Hz})$ ] of WBV, improved insulin resistance and liver oxidative stress (Liu et al., 2016). In a separate study also using the $\mathrm{db} / \mathrm{db}$ model, WBV decreased insulin resistance, attenuated hyperglycemia, and attenuated adipocyte hypertrophy in visceral adipose tissue compared to sedentary controls (McGee-Lawrence et al., 2017). Animal studies suggest the WBV may have a role in glycemic control, however, these findings have not been translated to the clinical setting.

In the clinical setting, a randomized interventional trial of 50 non-insulin dependent T2D patients randomized to a supervised exercise program (8 varied exercises performed on WBV platform) which included WBV $(f=12-16 \mathrm{~Hz})$ for 12 weeks or control, showed a reduction in HbA1c and fasting blood glucose (del Pozo-Cruz et al., 2014). In this study it was not possible to determine the individual effects of WBV without exercise. A meta-analysis of randomized trials on the effects of WBV in T2D patients also showed that WBV combined with exercise improves glycemic control (Robinson et al., 2016). The acute effects of WBV on T2D elderly women were studied using a single WBV session $(f=35 \mathrm{~Hz})$ in which exercise was not incorporated compared to controls. These investigators showed that both control and WBV group had a similar decline in postintervention glycemia (Pessoa et al., 2018) suggesting that acutely WBV does not independently modify glycemia.

A recent double blind randomized interventional trial comprising of 90 subjects with T2D randomized to 8 weeks of WBV $(f=12.5-18.5 \mathrm{~Hz})$ without additional exercise compared to control was unable to show differences in HbA1C, physical function or quality of life in these patients (Dominguez-Munoz et al., 2020). Taken together the above clinical studies suggest that WBV alone without a combine exercise intervention strategy may not have an effect on glycemic control. Questions remain as to whether or not higher or lower frequencies or higher amplitudes may confer benefit for glycemic control, but given the high discomfort profiles documented at lower frequencies and higher amplitudes these may not be appropriate (Huang and Zhang, 2019). Future studies of WBV should provide adherence to recent guidelines on the reporting or WBV parameters, such that comparisons can appropriately be made between and across studies (Wuestefeld et al., 2020).

\section{WHOLE BODY PERIODIC ACCELERATION}

\section{Whole Body Periodic Acceleration (WBPA, pGz) and Pulsatile Shear Stress}

Whole Body Periodic Acceleration also known as Periodic Acceleration in the $\mathrm{z}$ plane ( $\mathrm{pGz}$, in animal models) was fist described by Adams and Sackner over 20 years ago (Adams et al., 2000a,b). WBPA/pGz is the sinusoidal motion of the body in the supine posture in a headward to footward direction using a platform. The frequency of motion of the platform in humans is between 100 and 150 cycles per min $(1.6$ to $2.5 \mathrm{~Hz}$ ) with acceleration forces in the $\mathrm{z}$ plane $\mathrm{Gz} \pm 0.3 \mathrm{mt} / \mathrm{sec}^{2}$. In animal models pigs, rats, mice frequency of operation is 180 $(3 \mathrm{~Hz}), 360 \mathrm{cmp}(6 \mathrm{~Hz})$ and $480 \mathrm{cpm}(8 \mathrm{~Hz})$, respectively, with the same or similar acceleration forces as used in humans. The movement creates inertial forces which introduce small pulsations to the vasculature, these produce pulsatile shear stress to the vascular endothelium (Sackner et al., 2005a; Uryash et al., 2009). Similarly, to exercise and unlike EECP these pulsations are not synchronized with the cardiac cycle.

Whole Body Periodic Acceleration produces release of endothelial derived nitric oxide in human subjects (Fujita et al., 2005; Sackner et al., 2005b), and animal models (Uryash et al., 2009; Wu et al., 2009, 2012) and genomic upregulation of eNOS occurring over relatively short time period (Wu et al., 2009; Uryash et al., 2015). In addition to eNO, pGz increases expression of the antioxidants; superoxide dismutase, catalase, and total antioxidant capacity (Uryash et al., 2015), along with other endothelial derived anticoagulant, and vasoactive proteins and adrenomedullin (Adams et al., 2005; Martinez et al., 2008). WBPA used in human subjects with heart failure $(\mathrm{HF})$, coronary artery disease (CAD), angina, and peripheral artery disease (PAD) improved measures of quality of life in $\mathrm{HF}$, improved coronary flow reserve in CAD, increased exercise tolerance in angina, and improve walking distance and blood flow in PAD (Kohler et al., 2007; Miyamoto et al., 2011; Rokutanda et al., 2011; Sakaguchi et al., 2012; Takase et al., 2013). Due to the large dimensions (size of a single bed) weight $(\approx 225 \mathrm{Kg})$ cost $(\$ 10,000, £ 9,000)$ of the human platform, a smaller, simpler, device (a predicate device for WBPA) was designed to meet the needs for portability and user friendliness. A passive simulated jogging device [JD (Gentle Jogger, Sackner Wellness Products, Miami, FL, United States)] was created. The motorized JD, passively moves the feet in alternating motion simulating walking or jogging. With each down stroke of the fore foot a pulsation is added to the circulation, thus inducing pulsatile shear stress. The device can be used in the sitting or supine posture, weighs $<6 \mathrm{Kg}$, has a footprint of $12,300 \mathrm{~cm}^{3}$, and an approximate cost of 
less than $\$ 1,000$ ( $£ 750)$. JD is well tolerated and simple to operate for home use. Further, JD decreases sedentary behavior induced hypertension (Sackner et al., 2019), and improves short term heart rate variability in both supine and seated posture (Adams et al., 2018).

\section{Whole Body Periodic Acceleration (WBPA, pGz), Passive Simulated Jogging Device (JD) and Diabetes \\ Cellular Effects of pGz on Oxidative Stress}

The effects of $\mathrm{pGz}$ on various aspects of diabetes have been studied at the whole animals and cellular level. In a mouse model of type 1 diabetes, oxidative stress (Reactive Oxygen Species, ROS) was measured in isolated cardiomyocytes. Compared to control cardiomyocytes, ROS was increased $340 \%$. pGz performed for 14 days, $1 \mathrm{~h}$ daily in these mice decreased ROS production in cardiomyocytes by 50\% (Uryash et al., 2015).

\section{The Effects of $p G z$ on Diabetes Induced Calcium Dyshomeostasis}

We have determined whether or not pGz could modify intracellular $\mathrm{Ca}^{2+}$ dyshomeostasis produced by hyperglycemia in type 2 diabetic mice (T2D, C57BL/KsJ-db/db). Diabetic and age-matched controls mice were randomly divided into four groups of animals ( $n=5$ per group): (i) control (CONT), (ii) control pGz (pGz), (iii) Type 2 diabetic mice (T2D), and (iv) Type 2 diabetic mice treated with pGz (T2D-pGz). pGz treatment was performed on unanesthetized, restrained mice using the pGz platform ( $1 \mathrm{~h}$ per day $f=480 \mathrm{cpm}$ and $\mathrm{Gz} \pm 3.0 \mathrm{mt} / \mathrm{sec}^{2}$ ) for 14 consecutive days for both diabetic and controls. Single ventricular cardiomyocytes were isolated as previously described (Lopez et al., 1983; Eltit et al., 2013) and intracellular $\left[\mathrm{Ca}^{2+}\right]_{\mathrm{d}}$ determined in isolated cardiomyocytes by double-barreled selective microelectrodes (Mijares et al., 2014).

$\left[\mathrm{Ca}^{2+}\right]_{\mathrm{d}}$ was $122 \pm 3 \mathrm{nM}(n=20)$ in control polarized cardiomyocytes compared to $322 \pm 37 \mathrm{nM}(n=17)$ in T2D cardiomyocytes $(p \leq 0.05)$ (Figure 2 ). Treatment with $\mathrm{pGz}$ for 14 days reduced $\left[\mathrm{Ca}^{2+}\right]_{\mathrm{d}}$ by $46 \%$ in T2D cardiomyocytes mice (to $174 \pm 21 \mathrm{nM}, n=20)(p \leq 0.001$ compared to untreated age-matched T2D cardiomyocytes). In control cardiomyocytes, $\mathrm{pGz}$ did not significantly modify $\left[\mathrm{Ca}^{2+}\right]_{\mathrm{d}}(121 \pm 3 \mathrm{nM}, n=21$, $p \geq 0.05$ ) (unpublished results). The above findings confirm calcium dyshomeostasis in T2D mice, and show that pGz via PSS may be a coadjuvant candidate in preventing and treating calcium overload in diabetic cardiomyocytes.

\section{The Effects of WBPA and JD on Diabetes}

A single $1 \mathrm{~h}$ session of WBPA in T2D, reduced serum insulin and increased total and high molecular weight adiponectin, which acts as a key modulator of insulin sensitivity and glucose metabolism (Sakaguchi et al., 2012).

The effects of JD have also been studied in healthy volunteers and $\mathrm{T} 2 \mathrm{D}$ subjects in an at home clinical study. The effects were measured using interstitial continuous glucose monitoring (FreeStyle Libre Pro, Abbott, Alameda, CA, United States). There were no attempts to modify diet or usual activities

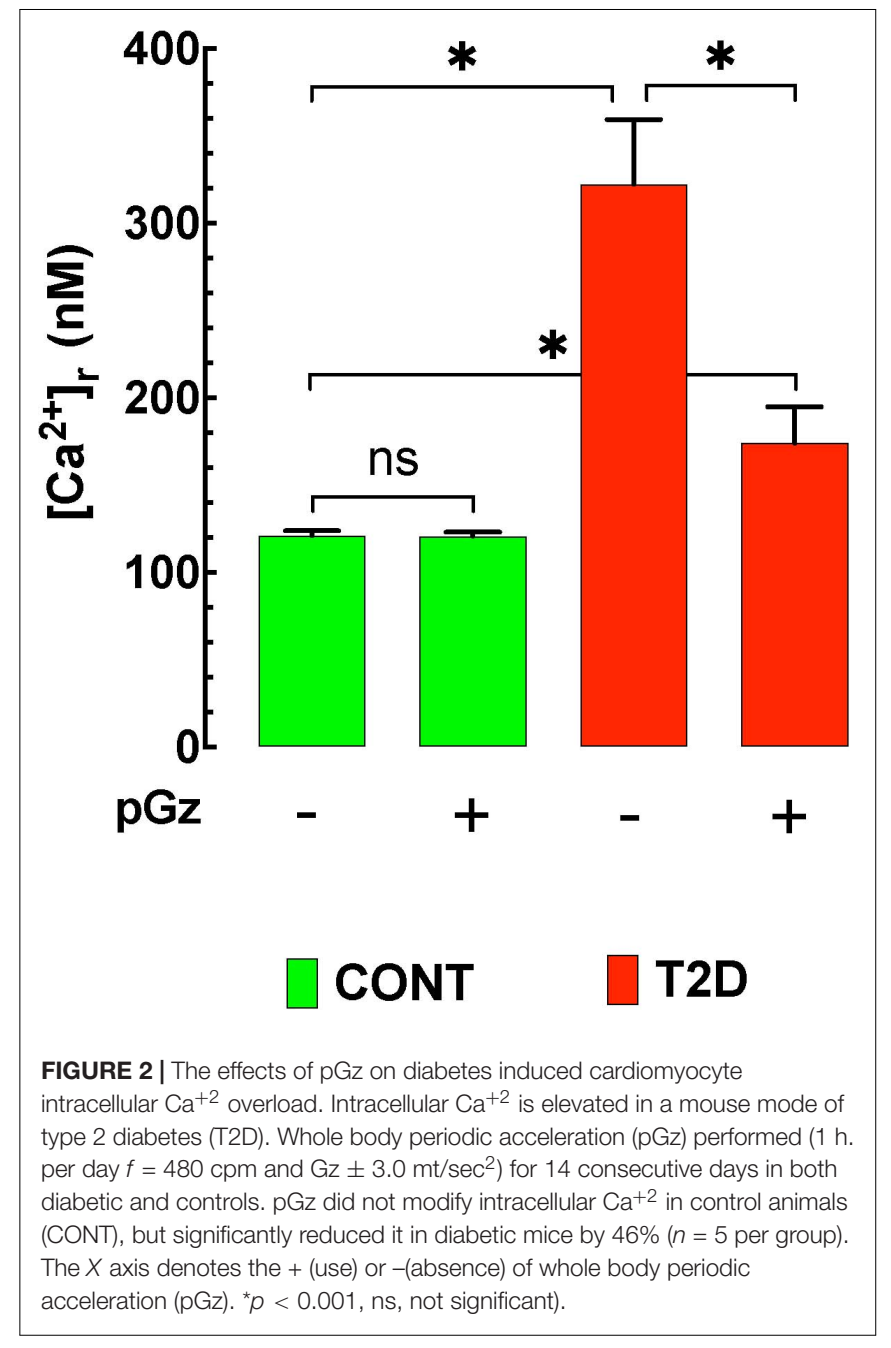

of daily living, all subjects continued to take their usual medications. Subjects were instructed to use the JD at least three times per day for $30 \mathrm{~min}$ for 7 days. Compliance with home use of the device was very good (98\% of subjects used the device 90 or more minutes per day). Continuous glucose monitoring showed; daily mean glucose, SUM of all glucose values, $24 \mathrm{~h}$ glucose area under the curve (24-AUC), were all significantly reduced from baseline values during the 7 day use of JD in both healthy and T2D. Additionally, time above glucose $>180 \mathrm{mg} / \mathrm{dl}$, was significantly reduced in T2D (Adams et al., 2020). Taken together these studies on WBPA/pGz and JD supports their beneficial effects on diabetes subjects.

The described methods to induce PSS are varied with respect to frequency, accelerations, and known effects on clinically measured aspects of diabetes. Nearly all of the methods have shown the biochemical effect of NO, anti-inflammatory, fibrinolysis, and improved endothelial function. They are also varied as to subject-device interface and portability. The characteristics of each of the aforementioned interventions to produce PSS, are summarized in Table 1. 
TABLE 1 | Comparison of methods to induce pulsatile shear stress.

\begin{tabular}{|c|c|c|c|c|c|}
\hline & Exercise & EECP & WBV & WBPA & JD \\
\hline $\begin{array}{l}\text { Root Mean Square } \\
\text { Acceleration (a }\left(\mathrm{a}_{\mathrm{RMS}}\right)\left(\mathrm{m} / \mathrm{s}^{2}\right.\end{array}$ & $1.5-2.5$ & $\mathrm{~N} / \mathrm{A}$ & $\begin{array}{l}\text { 2.1-7.0 dependent on amplitude, } \\
\text { f, and location of measurement } \\
\text { (Sonza et al., 2015) }\end{array}$ & $2.0-3.5$ & $1.0-3.0$ \\
\hline \multicolumn{6}{|l|}{ Biochemical Effect } \\
\hline Nitric Oxide Effect & $\uparrow$ & $\uparrow$ & $\mathrm{N} / \mathrm{A}$ & $\uparrow$ & $\uparrow$ \\
\hline eNO & $\uparrow$ & $\uparrow$ & $\mathrm{N} / \mathrm{A}$ & $\uparrow$ & $\uparrow$ \\
\hline Anti-Inflammatory & + & + & + & + & + \\
\hline Fibrinolysis & $\begin{array}{l}\text { Yes (Womack et al., } \\
\text { 2003) Uncertain (Patelis } \\
\text { et al., 2016) }\end{array}$ & $\begin{array}{l}\text { Yes (Comerota et al., } \\
\text { 1997) No Effect (Arora } \\
\text { et al., 2005) }\end{array}$ & $\mathrm{N} / \mathrm{A}$ & $\uparrow$ & $\uparrow$ \\
\hline Peak-Glucose & $\downarrow$ & $\mathrm{N} / \mathrm{A}$ & $\mathrm{N} / \mathrm{A}$ & $\downarrow$ & $\downarrow$ \\
\hline OGTT (AUC) & $\downarrow$ & $\downarrow$ & $\mathrm{N} / \mathrm{A}$ & N/A & $\downarrow$ \\
\hline Time in Glucose Range & Improves & $N / A$ & N/A & N/A & Improves \\
\hline $\mathrm{HbA1C}$ & $\downarrow$ & $\downarrow$ & $\downarrow$ or N.C & N/A & $\mathrm{N} / \mathrm{A}$ \\
\hline Improved Insulin Sensitivity & + & $N / A$ & $\mathrm{~N} / \mathrm{A}$ & + & $\mathrm{N} / \mathrm{A}$ \\
\hline $\begin{array}{l}\text { Improves Endothelial } \\
\text { Dysfunction }\end{array}$ & + & + & + & + & + \\
\hline \multicolumn{6}{|l|}{ Subject Usage } \\
\hline $\begin{array}{l}\text { Requires Cognitive/ } \\
\text { Physical Ability }\end{array}$ & YES & YES & YES & NO & NO \\
\hline Device Portability & $N / A$ & NO & NO (except commercial devices) & NO & YES \\
\hline
\end{tabular}

EECP, enhanced external counterpulsation; WBV, whole body vibration; WBPA, whole body periodic acceleration; JD, passive jogging device; eNO, endothelial derived nitric oxide; OGTT, oral glucose tolerance test; AUC, area under the curve. Time in Glucose Range = amount of time of plasma glucose <180 mg/dl in a $24 \mathrm{~h}$ period. $\uparrow=$ increase $\downarrow=$ decrease, N/A $=$ not available, N.C. $=$ no change, $+=$ positive effect.

\section{LIMITATIONS}

There are limitations in this present narrative review which must be acknowledged. The review has focused on 4 of the most common methods for sustained PSS, however, there are other methods such as vibro percussion (Hoffmann and Gill, 2012), and passive cycling or limb movement (Trinity et al., 2015; Hosseini et al., 2019), which may also have potential for diabetes therapeutics, but no studies are available on diabetics. Exercise is at the cornerstone of diabetes therapy, and the recommendations for exercise in T2D (Colberg et al., 2016; Piercy et al., 2018) provide guidance, however, we did not address in this review the optimum exercise prescription "dose" (duration, frequency, and intensity) the latter is a topic which remains largely unresolved (Durand and Gutterman, 2014; Pedersen and
Saltin, 2015; Simon, 2015; Wasfy and Baggish, 2016; Radak et al., 2017; Eijsvogels et al., 2018; Leggio et al., 2018; Ried-Larsen et al., 2018; Herold et al., 2019; Pedersen, 2019; Powers et al., 2020). It is also clear from the literature that any exercise is better than none, and that cumulative effects are better than single bouts. Recent Meta-analysis on the effects of exercise in T2D subjects on vascular endothelial function, have concluded that exercise training in general increases flow mediated vasodilation (FMD) particularly aerobic and combined aerobic and resistance exercise (Qiu et al., 2018), and low to moderate (50-70\% of heart rate $\max$, or 60-65\% oxygen consumption) intensity, increased FMD more than high intensity (Lee et al., 2018). We have also not discussed the value of interval training or high intensity interval training (HIIT) which potentially require less time commitment from the patients but greater subject 
engagement and fitness. A recent 1 year randomized controlled trial in patients with T2D showed that HIIT improved peripheral arterial stiffness and indices of distensibility (Magalhaes et al., 2019). In the recently reported D2FIT study (a 1 year randomized controlled study in T2D), non-exercise, moderate continuous training, resistance training (RT) and HIIT with RT, it appears that regardless of improvement in cardio respiratory fitness (peak oxygen consumption) with exercise, all interventions improved carotid intima-media thickness and pulse wave velocity markers of vascular health (Hetherington-Rauth et al., 2020). Further, a recent review on the inter-individual variability in the therapeutic response of blood glucose to exercise has identified knowledge gaps with regard to exercise dose, meal timing, antihyperglycemic drugs which must be addressed for optimizing therapeutic benefit of exercise (Solomon, 2018). It is clear that the overall goal of exercise in diabetes management is to decrease physical inactivity, exercise and the afore mentioned interventions all decrease physical inactivity. Higher levels of physical activity are associated with lower mortality rates in T2D (Geidl et al., 2020). Finally, we have not addressed adherence and barriers to exercise or the aforementioned interventions. Reduced adherence to physical activity guidelines in diabetics are associated with daily smoking, obesity chronic kidney disease and poor health and the latter associated with barriers such as pain, fatigue, physical limitations and hospitalizations (Barker and Eickmeyer, 2020; Martinez-Harvell et al., 2020). The interventions discussed in this review are not intended to take precedent over any exercise regimen, they are targeted to the population of subjects who cannot or will not exercise.

\section{REFERENCES}

Adams, J. A., Banderas, V., Lopez, J. R., and Sackner, M. A. (2020). Portable gentle jogger improves glycemic indices in type 2 diabetic and healthy subjects living at home: a pilot study. J. Diabetes Res. 2020:8317973.

Adams, J. A., Bassuk, J., Wu, D., Grana, M., Kurlansky, P., and Sackner, M. A. (2005). Periodic acceleration: effects on vasoactive, fibrinolytic, and coagulation factors. J. Appl. Physiol. 98, 1083-1090. doi: 10.1152/japplphysiol.00662. 2004

Adams, J. A., Mangino, M. J., Bassuk, J., Inman, D. M., and Sackner, M. A. (2000a). Non-invasive motion ventilation (NIMV): a novel approach to ventilatory support. J. Appl. Physiol. 89, 2438-2446. doi: 10.1152/jappl.2000.89.6.2438

Adams, J. A., Mangino, M. J., Bassuk, J., and Sackner, M. A. (2000b). Hemodynamic effects of periodic $\mathrm{G}(\mathrm{z})$ acceleration in meconium aspiration in pigs. J. Appl. Physiol. 89, 2447-2452. doi: 10.1152/jappl.2000.89.6.2447

Adams, J. A., Patel, S., Lopez, J. R., and Sackner, M. A. (2018). The effects of passive simulated jogging on short-term heart rate variability in a heterogeneous group of human subjects. J. Sports Med. 2018:4340925.

Adams, V., Reich, B., Uhlemann, M., and Niebauer, J. (2017). Molecular effects of exercise training in patients with cardiovascular disease: focus on skeletal muscle, endothelium, and myocardium. Am. J. Physiol. Heart Circ. Physiol. 313, $\mathrm{H} 72-\mathrm{H} 88$.

Ahlbom, M., Hagerman, I., Stahlberg, M., Manouras, A., Forstedt, G., Wu, E., et al. (2016). Increases in cardiac output and oxygen consumption during enhanced external counterpulsation. Heart Lung Circ. 25, 1133-1136. doi: 10.1016/j.hlc. 2016.04.013

Aird, W. C. (2003). Endothelial cell heterogeneity. Crit. Care Med. 31, S221-S230.

Ajami, N. E., Gupta, S., Maurya, M. R., Nguyen, P., Li, J. Y., Shyy, J. Y., et al. (2017). Systems biology analysis of longitudinal functional response of endothelial cells to shear stress. Proc. Natl. Acad. Sci. U S A. 114, 10990-10995. doi: 10.1073/ pnas. 1707517114

\section{CONCLUSION}

Pulsatile Shear Stress, to the vascular endothelium is clinically feasible and a potential therapeutic intervention in the management of diabetes. In subjects for whom physical exercise is not possible both EECP and JD are strategies which are easily used. The vasculoprotective, antioxidant, anti-inflammatory, and glucose lowering, effects of PSS can be harnessed to improve management and outcomes from diabetes and other chronic conditions. Given the magnitude of physical inactivity worldwide, PSS via non-invasive methods are plausible stop gap alternatives for those who can't or won't exercise. Further studies are needed to ascertain the optimum duration of use of these devices, and additional mechanistic insights.

\section{AUTHOR CONTRIBUTIONS}

JA conceived and wrote the initial manuscript. AU performed the laboratory experiments and edited the manuscript. JL performed the experiments and co-wrote the manuscript. MS co-wrote and edited the manuscript. All authors contributed to the article and approved the submitted version.

\section{FUNDING}

This work was funded by a grant from the Florida Heart Research Institute (Miami, FL, United States) awarded to JA.

Akhtar, M., Wu, G. F., Du, Z. M., Zheng, Z. S., and Michaels, A. D. (2006). Effect of external counterpulsation on plasma nitric oxide and endothelin-1 levels. Am. J. Cardiol. 98, 28-30. doi: 10.1016/j.amjcard.2006.01.053

Albrecht, E. W., Stegeman, C. A., Heeringa, P., Henning, R. H., and van Goor, H. (2003). Protective role of endothelial nitric oxide synthase. J. Pathol. 199, 8-17.

American Diabetes, A. (2020). 10. Cardiovascular disease and risk management: standards of medical care in diabetes-2020. Diabetes Care 43, S111-S134.

Aoyama, A., Yamaoka-Tojo, M., Obara, S., Shimizu, E., Fujiyoshi, K., Noda, C., et al. (2019). Acute effects of whole-body vibration training on endothelial function and cardiovascular response in elderly patients with cardiovascular disease. Int. Heart J. 60, 854-861. doi: 10.1536/ihj.18-592

Arora, R., Chen, H. J., and Rabbani, L. (2005). Effects of enhanced counterpulsation on vascular cell release of coagulation factors. Heart Lung 34, 252-256. doi: 10.1016/j.hrtlng.2005.03.005

Barker, K., and Eickmeyer, S. (2020). Therapeutic exercise. Med. Clin. North Am. 104, 189-198.

Bender, S. B., and Laughlin, M. H. (2015). Modulation of endothelial cell phenotype by physical activity: impact on obesity-related endothelial dysfunction. Am. J. Physiol. Heart Circ. Physiol. 309, H1-H8.

Berbudi, A., Rahmadika, N., Tjahjadi, A. I., and Ruslami, R. (2020). Type 2 diabetes and its impact on the immune system. Curr. Diabetes Rev. 16, 442-449. doi: $10.2174 / 1573399815666191024085838$

Bommer, C., Sagalova, V., Heesemann, E., Manne-Goehler, J., Atun, R., Barnighausen, T., et al. (2018). Global economic burden of diabetes in adults: projections from 2015 to 2030. Diabetes Care 41, 963-970. doi: 10.2337/dc171962

Braith, R. W., Casey, D. P., and Beck, D. T. (2012). Enhanced external counterpulsation for ischemic heart disease: a look behind the curtain. Exerc. Sport Sci. Rev. 40, 145-152. doi: 10.1097/jes.0b013e318253de5e

Braith, R. W., Conti, C. R., Nichols, W. W., Choi, C. Y., Khuddus, M. A., Beck, D. T., et al. (2010). Enhanced external counterpulsation improves 
peripheral artery flow-mediated dilation in patients with chronic angina: a randomized sham-controlled study. Circulation 122, 1612-1620. doi: 10.1161/ circulationaha.109.923482

Brown, E. C., Franklin, B. A., Regensteiner, J. G., and Stewart, K. J. (2020). Effects of single bout resistance exercise on glucose levels, insulin action, and cardiovascular risk in type 2 diabetes: a narrative review. J. Diabetes Complications 34:107610. doi: 10.1016/j.jdiacomp.2020.107610

Bryan, M. T., Duckles, H., Feng, S., Hsiao, S. T., Kim, H. R., Serbanovic-Canic, J., et al. (2014). Mechanoresponsive networks controlling vascular inflammation. Arterioscler Thromb. Vasc. Biol. 34, 2199-2205. doi: 10.1161/atvbaha.114. 303424

Campinho, P., Vilfan, A., and Vermot, J. (2020). Blood flow forces in shaping the vascular system: a focus on endothelial cell behavior. Front. Physiol. 11:552. doi: $10.3389 /$ fphys.2020.00552

Cardinale, M., and Wakeling, J. (2005). Whole body vibration exercise: are vibrations good for you? Br. J. Sports Med. 39, 585-589. doi: 10.1136/bjsm. 2005.016857

Chien, S. (2007). Mechanotransduction and endothelial cell homeostasis: the wisdom of the cell. Am. J. Physiol. Heart Circ. Physiol. 292, H1209-H1224.

Cirino, G., Fiorucci, S., and Sessa, W. C. (2003). Endothelial nitric oxide synthase: the cinderella of inflammation? Trends Pharmacol. Sci. 24, 91-95. doi: 10.1016/ s0165-6147(02)00049-4

Clermont, C. A., Benson, L. C., Osis, S. T., Kobsar, D., and Ferber, R. (2019). Running patterns for male and female competitive and recreational runners based on accelerometer data. J. Sports Sci. 37, 204-211. doi: 10.1080/02640414. 2018.1488518

Colberg, S. R., Sigal, R. J., Yardley, J. E., Riddell, M. C., Dunstan, D. W., Dempsey, P. C., et al. (2016). Physical activity/exercise and diabetes: a position statement of the american diabetes association. Diabetes Care 39, 2065-2079.

Comerota, A. J., Chouhan, V., Harada, R. N., Sun, L., Hosking, J., Veermansunemi, R., et al. (1997). The fibrinolytic effects of intermittent pneumatic compression: mechanism of enhanced fibrinolysis. Ann. Surg. 226, 306-314. doi: 10.1097/ 00000658-199709000-00010

Cyr, A. R., Huckaby, L. V., Shiva, S. S., and Zuckerbraun, B. S. (2020). Nitric oxide and endothelial dysfunction. Crit. Care Clin. 36, 307-321.

Davies, P. F. (1995). Flow-mediated endothelial mechanotransduction. Physiol. Rev. 75, 519-560. doi: 10.1152/physrev.1995.75.3.519

del Pozo-Cruz, B., Alfonso-Rosa, R. M., del Pozo-Cruz, J., Sañudo, B., and Rogers, M. E. (2014). Effects of a 12-wk whole-body vibration based intervention to improve type 2 diabetes. Maturitas 77, 52-58. doi: 10.1016/j.maturitas.2013. 09.005

Dohm, G. L. (2002). Invited review: regulation of skeletal muscle GLUT-4 expression by exercise. J. Appl. Physiol. 93, 782-787. doi: 10.1152/japplphysiol. 01266.2001

Dominguez-Munoz, F. J., Villafaina, S., Garcia-Gordillo, M. A., HernandezMocholi, M. A., Collado-Mateo, D., Adsuar, J. C., et al. (2020). Effects of 8-week whole-body vibration training on the $\mathrm{HbA1c}$, quality of life, physical fitness, body composition and foot health status in people with T2DM: a doubleblinded randomized controlled trial. Int. J. Environ. Res. Public Health 17:1317. doi: 10.3390/ijerph17041317

Duran, W. N., Beuve, A. V., and Sanchez, F. A. (2013). Nitric oxide, S-Nitrosation, and endothelial permeability. IUBMB Life 65, 819-826. doi: 10.1002/iub.1204

Durand, M. J., and Gutterman, D. D. (2014). Exercise and vascular function: how much is too much? Can. J. Physiol. Pharmacol. 92, 551-557. doi: 10.1139/cjpp2013-0486

Eijsvogels, T. M. H., Thompson, P. D., and Franklin, B. A. (2018). The extreme exercise hypothesis": recent findings and cardiovascular health implications. Curr. Treat Opt. Cardiovasc. Med. 20:84.

Eltit, J. M., Ding, X. I, Pessah, N., Allen, P. D., and Lopez, J. R. (2013). Non-specific sarcolemmal cation channels are critical for the pathogenesis of malignant hyperthermia. FASEB J. 27, 991-1000. doi: 10.1096/fj.12-218354

Farah, C., Michel, L. Y. M., and Balligand, J.-L. (2018). Nitric oxide signalling in cardiovascular health and disease. Nat. Rev. Cardiol. 15, 292-316. doi: 10.1038/ nrcardio.2017.224

Fares, E. J., Charriere, N., Montani, J. P., Schutz, Y., Dulloo, A. G., Miles-Chan, J. L. et al. (2016). Energy expenditure and substrate oxidation in response to side-alternating whole body vibration across three commonly-used vibration frequencies. PLoS One 11:e0151552. doi: 10.1371/journal.pone.0151552
Filardi, T., Ghinassi, B., Di Baldassarre, A., Tanzilli, G., Morano, S., Lenzi, A., et al. (2019). Cardiomyopathy associated with diabetes: the central role of the cardiomyocyte. Int. J. Mol. Sci. 20:3299. doi: 10.3390/ijms20133299

Firasat, S., Hecker, M., Binder, L., and Asif, A. R. (2014). Advances in endothelial shear stress proteomics. Exp. Rev. Proteomics 11, 611-619. doi: 10.1586/ 14789450.2014 .933673

Fischer, M., Vialleron, T., Laffaye, G., Fourcade, P., Hussein, T., Cheze, L., et al. (2019). Long-term effects of whole-body vibration on human gait: a systematic review and meta-analysis. Front. Neurol. 10:627. doi: 10.3389/fneur.2019.00627

Fletcher, G. F., Landolfo, C., Niebauer, J., Ozemek, C., Arena, R., Lavie, C. J. et al. (2018). Reprint of: promoting physical activity and exercise: jacc health promotion series. J. Am. Coll. Cardiol. 72, 3053-3070.

Forstermann, U., and Sessa, W. C. (2012). Nitric oxide synthases: regulation and function. Eur. Heart J. 33, 829-837. doi: 10.1093/eurheartj/ehr304

Fujita, M., Tambara, K., Ikemoto, M., Sakamoto, S., Ogai, A., Kitakaze, M., et al. (2005). Periodic acceleration enhances release of nitric oxide in healthy adults. Int. J. Angiol. 14, 11-14. doi: 10.1007/s00547-005-2013-2

Games, K. E., Sefton, J. M., and Wilson, A. E. (2015). Whole-body vibration and blood flow and muscle oxygenation: a meta-analysis. J. Athl. Train 50, 542-549. doi: 10.4085/1062-6050-50.2.09

Geidl, W., Schlesinger, S., Mino, E., Miranda, L., and Pfeifer, K. (2020). Dose-response relationship between physical activity and mortality in adults with non-communicable diseases: a systematic review and meta-analysis of prospective observational studies. Int. J. Behav. Nutr. Phys. Act 17:109.

Ghimire, K., Altmann, H. M., Straub, A. C., and Isenberg, J. S. (2017). Nitric oxide: what's new to NO? Am. J. Physiol. Cell. Physiol. 312, C254-C262.

Goetz, C. G. (2009). Jean-martin charcot and his vibratory chair for parkinson disease. Neurology 73, 475-478. doi: 10.1212/wnl.0b013e3181b1640b

Goligorsky, M. S. (2017). Vascular endothelium in diabetes. Am. J. Physiol. Renal. Physiol. 312, F266-F275.

Gordon, E., Schimmel, L., and Frye, M. (2020). The importance of mechanical forces for in vitro endothelial cell biology. Front. Physiol. 11:684. doi: 10.3389/ fphys.2020.00684

Green, D. J., Hopman, M. T., Padilla, J., Laughlin, M. H., and Thijssen, D. H. (2017). Vascular adaptation to exercise in humans: role of hemodynamic stimuli. Physiol. Rev. 97, 495-528. doi: 10.1152/physrev.00014.2016

Green, D. J., and Smith, K. J. (2018). Effects of exercise on vascular function, structure, and health in humans. Cold Spring Harb. Perspect. Med. 8:a029819. doi: $10.1101 /$ cshperspect.a029819

Guerrero-Hernandez, A., and Verkhratsky, A. (2014). Calcium signalling in diabetes. Cell. Calcium 56, 297-301. doi: 10.1016/j.ceca.2014.08.009

Hadi, H. A., Carr, C. S., and Al Suwaidi, J. (2005). Endothelial dysfunction: cardiovascular risk factors, therapy, and outcome. Vasc. Health Risk Manag. 1, 183-198.

He, M., Martin, M., Marin, T., Chen, Z., and Gongol, B. (2020). Endothelial mechanobiology. APL Bioeng. 4:010904.

Henriksen, E. J. (2002). Invited review: effects of acute exercise and exercise training on insulin resistance. J. Appl. Physiol. 93, 788-796. doi: 10.1152/ japplphysiol.01219.2001

Herold, F., Muller, P., Gronwald, T., and Muller, N. G. (2019). Dose-response matters! - a perspective on the exercise prescription in exercise-cognition research. Front. Psychol. 10:2338. doi: 10.3389/fpsyg.2019.02338

Hetherington-Rauth, M., Magalhaes, J. P., Judice, P. B., Melo, X., and Sardinha, L. B. (2020). Vascular improvements in individuals with type 2 diabetes following a 1 year randomised controlled exercise intervention, irrespective of changes in cardiorespiratory fitness. Diabetologia 63, 722-732. doi: 10.1007/ s00125-020-05089-5

Himburg, H. A., Dowd, S. E., and Friedman, M. H. (2007). Frequency-dependent response of the vascular endothelium to pulsatile shear stress. Am. J. Physiol. Heart Circ. Physiol. 293, H645-H653.

Hoffmann, A., and Gill, H. (2012). Diastolic timed vibro-percussion at $50 \mathrm{~Hz}$ delivered across a chest wall sized meat barrier enhances clot dissolution and remotely administered Streptokinase effectiveness in an in vitro model of acute coronary thrombosis. Thromb .J. 10:23. doi: 10.1186/1477-9560-10-23

Hoover, G. N., Ashe, W. F., Dines, J. H., and Fraser, T. M. (1961). Vibration studies. III. Blood pressure responses to whole-body vibration in anesthetized dogs. Arch. Environ. Health 3, 426-432. doi: 10.1080/00039896.1961.1066 3045 
Hosseini, Z. S., Peyrovi, H., and Gohari, M. (2019). The effect of early passive range of motion exercise on motor function of people with stroke: a randomized controlled trial. J. Caring. Sci. 8, 39-44. doi: 10.15171/jcs.2019.006

Huang, Y., and Zhang, P. (2019). Subjective discomfort caused by vertical wholebody vibration in the frequency range 2-100 Hz. Ergonomics 62, 420-430. doi: 10.1080/00140139.2018.1533145

Hutcheson, I. R., and Griffith, T. M. (1991). Release of endothelium-derived relaxing factor is modulated both by frequency and amplitude of pulsatile flow. Am. J. Physiol. 261, H257-H262.

Ito, Y., Obara, K., Ikeda, R., Ishii, M., Tanabe, Y., Ishikawa, T., et al. (2006). Passive stretching produces Akt- and MAPK-dependent augmentations of GLUT4 translocation and glucose uptake in skeletal muscles of mice. Pflugers Arch. 451, 803-813. doi: 10.1007/s00424-005-1512-5

Jan, R., Khan, A., Zahid, S., Sami, A., Owais, S. M., Khan, F., et al. (2020). The effect of enhanced external counterpulsation (EECP) on quality of life in patient with coronary artery disease not amenable to PCI or CABG. Cureus 12:e7987.

Jia, G., Hill, M. A., and Sowers, J. R. (2018). Diabetic cardiomyopathy: an update of mechanisms contributing to this clinical entity. Circ. Res. 122, 624-638. doi: 10.1161/circresaha.117.311586

Johnson, P. K., Feland, J. B., Johnson, A. W., Mack, G. W., and Mitchell, U. H. (2014). Effect of whole body vibration on skin blood flow and nitric oxide production. J. Diabetes Sci. Technol. 8, 889-894. doi: 10.1177/ 1932296814536289

Joubert, M., Manrique, A., Cariou, B., and Prieur, X. (2019). Diabetes-related cardiomyopathy: the sweet story of glucose overload from epidemiology to cellular pathways. Diabetes Metab. 45, 238-247. doi: 10.1016/j.diabet.2018. 07.003

Kadohama, T., Nishimura, K., Hoshino, Y., Sasajima, T., and Sumpio, B. E. (2007). Effects of different types of fluid shear stress on endothelial cell proliferation and survival. J. Cell. Physiol. 212, 244-251. doi: 10.1002/jcp.21024

Kantrowitz, A. (1953). Experimental augmentation of coronary flow by retardation of the arterial pressure pulse. Surgery 34, 678-687.

Kawabata, M., Goto, K., Fukusaki, C., Sasaki, K., Hihara, E., Mizushina, T., et al. (2013). Acceleration patterns in the lower and upper trunk during running. J. Sports Sci. 31, 1841-1853. doi: 10.1080/02640414.2013.805884

Kellogg, J. H. (1908). The Art of Massage its Physiological Effects and Therapeutic Applications. Sacramento, California: Modern Medicine Publishing Co.

Kohler, M., Amann-Vesti, B. R., Clarenbach, C. F., Brack, T., Noll, G., Russi, E. W., et al. (2007). Periodic whole body acceleration: a novel therapy for cardiovascular disease. Vasa 36, 261-266. doi: 10.1024/0301-1526.36.4.261

Kojda, G., and Hambrecht, R. (2005). Molecular mechanisms of vascular adaptations to exercise. Physical activity as an effective antioxidant therapy? Cardiovasc. Res. 67, 187-197. doi: 10.1016/j.cardiores.2005.04.032

Kolluru, G. K., Siamwala, J. H., and Chatterjee, S. (2010). eNOS phosphorylation in health and disease. Biochimie 92, 1186-1198. doi: 10.1016/j.biochi.2010.03.020

Kruger-Genge, A., Blocki, A., Franke, R. P., and Jung, F. (2019). Vascular endothelial cell biology: an update. Int. J. Mol. Sci. 20:4411. doi: 10.3390/ ijms 20184411

Laughlin, M. H., Newcomer, S. C., and Bender, S. B. (2008). Importance of hemodynamic forces as signals for exercise-induced changes in endothelial cell phenotype. J. Appl. Physiol. 104, 588-600. doi: 10.1152/japplphysiol.01096.2007

Lee, J. H., Lee, R., Hwang, M. H., Hamilton, M. T., and Park, Y. (2018). The effects of exercise on vascular endothelial function in type 2 diabetes: a systematic review and meta-analysis. Diabetol. Metab. Syndr. 10:15.

Leggio, M., Bendini, M. G., D’Emidio, S., Caldarone, E., Lombardi, M., Severi, P., et al. (2018). Exercise dose in clinical practice: right is better than more. Cardiol. J. 25, 287-288. doi: 10.5603/cj.2018.0040

Li, B., Wang, W., Mao, B., Yang, H., Niu, H., Du, J., et al. (2019). Longterm hemodynamic mechanism of enhanced external counterpulsation in the treatment of coronary heart disease: a geometric multiscale simulation. Med. Biol. Eng. Comput. 57, 2417-2433. doi: 10.1007/s11517-019-02028-4

Lin, S., Xiao-Ming, W., and Gui-Fu, W. (2020). Expert consensus on the clinical application of enhanced external counterpulsation in elderly people (2019). Aging. Med. 3, 16-24. doi: 10.1002/clc.4960251406

Liu, Y., Zhai, M., Guo, F., Shi, T., Liu, J., Wang, X., et al. (2016). Whole body vibration improves insulin resistance in $\mathrm{db} / \mathrm{db}$ mice: amelioration of lipid accumulation and oxidative stress. Appl. Biochem. Biotechnol. 179, 819-829. doi: 10.1007/s12010-016-2033-8
Lopez, J. R., Alamo, L., Caputo, C., DiPolo, R., and Vergara, S. (1983). Determination of ionic calcium in frog skeletal muscle fibers. Biophys. J. 43, 1-4. doi: 10.1016/s0006-3495(83)84316-1

Magalhaes, J. P., Melo, X. I, Correia, R., Ribeiro, R. T., Raposo, J., Dores, H., et al. (2019). Effects of combined training with different intensities on vascular health in patients with type 2 diabetes: a 1-year randomized controlled trial. Cardiovasc. Diabetol. 18:34.

Martin, J. S., Beck, D. T., Aranda, J. M. Jr., and Braith, R. W. (2012). Enhanced external counterpulsation improves peripheral artery function and glucose tolerance in subjects with abnormal glucose tolerance. J. Appl. Physiol. 112, 868-876. doi: 10.1152/japplphysiol.01336.2011

Martin, J. S., Beck, D. T., and Braith, R. W. (2014). Peripheral resistance artery blood flow in subjects with abnormal glucose tolerance is improved following enhanced external counterpulsation therapy. Appl. Physiol. Nutr. Metab. 39, 596-599. doi: 10.1139/apnm-2013-0497

Martin, J. S., and Braith, R. W. (2012). Anti-inflammatory effects of enhanced external counterpulsation in subjects with abnormal glucose tolerance. Appl. Physiol. Nutr. Metab. 37, 1251-1255. doi: 10.1139/h2012-112

Martinez, A., Arias, J., Bassuk, J. A., Wu, H., Kurlansky, P., Adams, J. A. et al. (2008). Adrenomedullin is increased by pulsatile shear stress on the vascular endothelium via periodic acceleration (pGz). Peptides 29, 73-78. doi: 10.1016/ j.peptides.2007.10.021

Martinez-Harvell, G., Goluboff, F., Rodriguez, P., Castro, G., and Barengo, N. C. (2020). Predictors of adherence to physical activity guidelines in patients with diabetes mellitus in the US in 2017: An exploratory analysis. Prim. Care Diabetes 14, 645-653. doi: 10.1016/j.pcd.2020.05.001

McGee-Lawrence, M. E., Wenger, K. H., Misra, S., Davis, C. L., Pollock, N. K., Elsalanty, M., et al. (2017). Whole-body vibration mimics the metabolic effects of exercise in male leptin receptor-deficient mice. Endocrinology 158, 11601171. doi: 10.1210/en.2016-1250

McKenna, C., Hawkins, N., Claxton, K., McDaid, C., Suekarran, S., Light, K., et al. (2010). Cost-effectiveness of enhanced external counterpulsation (EECP) for the treatment of stable angina in the united kingdom. Int. J. Technol. Assess. Health Care 26, 175-182. doi: 10.1017/s0266462310000073

Meza, C. A., La Favor, J. D., Kim, D. H., and Hickner, R. C. (2019). Endothelial dysfunction: is there a hyperglycemia-induced imbalance of NOX and NOS? Int. J. Mol. Sci. 20:3775. doi: 10.3390/ijms20153775

Mijares, A., Altamirano, F., Kolster, J., Adams, J. A., and Lopez, J. R. (2014). Age-dependent changes in diastolic $\mathrm{Ca}(2+)$ and $\mathrm{Na}(+)$ concentrations in dystrophic cardiomyopathy: role of $\mathrm{Ca}(2+)$ entry and IP3. Biochem. Biophys. Res. Commun. 452, 1054-1059. doi: 10.1016/j.bbrc.2014.09.045

Miyamoto, S., Fujita, M., Inoko, M., Oba, M., Hosokawa, R., Haruna, T., et al. (2011). Effect on treadmill exercise capacity, myocardial ischemia, and left ventricular function as a result of repeated whole-body periodic acceleration with heparin pretreatment in patients with angina pectoris and mild left ventricular dysfunction. Am. J. Cardiol. 107, 168-174. doi: 10.1016/j.amjcard. 2010.09.007

Murtaza, G., Virk, H. U. H., Khalid, M., Lavie, C. J., Ventura, H., Mukherjee, D., et al. (2019). Diabetic cardiomyopathy - a comprehensive updated review. Prog. Cardiovasc. Dis. 62, 315-326. doi: 10.1016/j.pcad.2019.03.003

Nakamura, M., and Sadoshima, J. (2020). Cardiomyopathy in obesity, insulin resistance and diabetes. J. Physiol. 598, 2977-2993. doi: 10.1113/jp27 6747

Ohura, N., Yamamoto, K., Ichioka, S., Sokabe, T., Nakatsuka, H., Baba, A., et al. (2003). Global analysis of shear stress-responsive genes in vascular endothelial cells. J. Atheroscler. Thromb. 10, 304-313. doi: 10.5551/jat.10.304

Patelis, N., Karaolanis, G., Kouvelos, G. N., Hart, C., and Metheiken, S. (2016). The effect of exercise on coagulation and fibrinolysis factors in patients with peripheral arterial disease. Exp. Biol. Med. 241, 1699-1707. doi: 10.1177/ 1535370216660215

Pedersen, B. K. (2019). The physiology of optimizing health with a focus on exercise as medicine. Annu. Rev. Physiol. 81, 607-627. doi: 10.1146/annurev-physiol020518-114339

Pedersen, B. K., and Saltin, B. (2015). Exercise as medicine - evidence for prescribing exercise as therapy in 26 different chronic diseases. Scand J. Med. Sci. Sports 25, 1-72. doi: 10.1111/sms.12581

Pessoa, M. F., de Souza, H. C. M., da Silva, A. P. V., Clemente, R. D. S., Brandão, D. C., Dornelas de Andrade, A. et al. (2018). Acute whole body vibration 
decreases the glucose levels in elderly diabetic women. Rehabil. Res. Pract. 2018:3820615.

Petersen, M. C., and Shulman, G. I. (2018). Mechanisms of insulin action and insulin resistance. Physiol. Rev. 98, 2133-2223. doi: 10.1152/physrev.00063. 2017

Piercy, K. L., Troiano, R. P., Ballard, R. M., Carlson, S. A., Fulton, J. E., Galuska, D. A., et al. (2018). The physical activity guidelines for americans. JAMA 320, 2020-2028.

Pinckard, K., Baskin, K. K., and Stanford, K. I. (2019). Effects of exercise to improve cardiovascular health. Front. Cardiovasc. Med. 6:69. doi: 10.3389/fcvm.2019. 00069

Ploughman, M. (2008). Exercise is brain food: the effects of physical activity on cognitive function. Dev. Neurorehabilitation 11, 236-240. doi: 10.1080/ 17518420801997007

Powers, S. K., Deminice, R., Ozdemir, M., Yoshihara, T., Bomkamp, M. P., and Hyatt, H. (2020). Exercise-induced oxidative stress: friend or foe? J. Sport Health Sci. 9, 415-425. doi: 10.1016/j.jshs.2020.04.001

Qiu, S., Cai, X., Yin, H., Sun, Z., Zugel, M., Steinacker, J. M., et al. (2018). Exercise training and endothelial function in patients with type 2 diabetes: a meta-analysis. Cardiovasc. Diabetol. 17:64.

Qiu, Y., and Tarbell, J. M. (2000). Interaction between wall shear stress and circumferential strain affects endothelial cell biochemical production. J. Vasc. Res. 37, 147-157. doi: 10.1159/000025726

Radak, Z., Ishihara, K., Tekus, E., Varga, C., Posa, A., Balogh, L., et al. (2017). Exercise, oxidants, and antioxidants change the shape of the bell-shaped hormesis curve. Redox. Biol. 12, 285-290. doi: 10.1016/j.redox.2017.02.015

Rawer, R. (2020). Manual of Vibration Exercise and Vibration Therapy. New York City, NY: Springer International Publishing.

Raza, A., Steinberg, K., Tartaglia, J., Frishman, W. H., and Gupta, T. (2017). Enhanced external counterpulsation therapy: past, present, and future. Cardiol. Rev. 25, 59-67. doi: 10.1097/crd.0000000000000122

Resnick, N., Yahav, H., Shay-Salit, A., Shushy, M., Schubert, S., Zilberman, L. C., et al. (2003). Fluid shear stress and the vascular endothelium: for better and for worse. Prog. Biophy. Mol. Biol. 81, 177-199. doi: 10.1016/s0079-6107(02) 00052-4

Richter, E. A., and Hargreaves, M. (2013). Exercise, GLUT4, and skeletal muscle glucose uptake. Physiol. Rev. 93, 993-1017. doi: 10.1152/physrev.00038.2012

Ried-Larsen, M., MacDonald, C. S., Johansen, M. Y., Hansen, K. B., Christensen, R., Almdal, T. P., et al. (2018). Why prescribe exercise as therapy in type 2 diabetes? We have a pill for that! Diabetes Metab. Res. Rev. 34:e2999. doi: 10.1002/dmrr.2999

Rittweger, J. (2010). Vibration as an exercise modality: how it may work, and what its potential might be. Eur. J. Appl. Physiol. 108, 877-904. doi: 10.1007/s00421009-1303-3

Robbins, D., Yoganathan, P., and Goss-Sampson, M. (2014). The influence of whole body vibration on the central and peripheral cardiovascular system. Clin. Physiol. Funct. Imaging 34, 364-369. doi: 10.1111/cpf.12103

Robinson, C. C., Barreto, R. P., Sbruzzi, G., and Plentz, R. D. (2016). The effects of whole body vibration in patients with type 2 diabetes: a systematic review and meta-analysis of randomized controlled trials. Braz. J. Phys. Ther. 20, 4-14. doi: 10.1590/bjpt-rbf.2014.0133

Rokutanda, T., Izumiya, Y., Miura, M., Fukuda, S., Shimada, K., Izumi, Y., et al. (2011). Passive exercise using whole-body periodic acceleration enhances blood supply to ischemic hindlimb. Arterioscler Thromb. Vasc. Biol. 31, 2872-2880. doi: 10.1161/atvbaha.111.229773

Roux, E., Bougaran, P., Dufourcq, P., and Couffinhal, T. (2020). Fluid shear stress sensing by the endothelial layer. Front. Physiol. 11:861. doi: 10.3389/fphys.2020. 00861

Sackner, M. A., Gummels, E., and Adams, J. A. (2005a). Effect of moderateintensity exercise, whole-body periodic acceleration, and passive cycling on nitric oxide release into circulation. Chest 128, 2794-2803. doi: 10.1378/chest. 128.4.2794

Sackner, M. A., Gummels, E., and Adams, J. A. (2005b). Nitric oxide is released into circulation with whole-body, periodic acceleration. Chest 127, 30-39. doi: 10.1378/chest.127.1.30

Sackner, M. A., Lopez, J. R., Banderas, V., and Adams, J. A. (2020). Can physical activity while sedentary produce health benefits? a single-arm randomized trial. Sports Med. Open 6:47.
Sackner, M. A., Patel, S., and Adams, J. A. (2019). Changes of blood pressure following initiation of physical inactivity and after external addition of pulses to circulation. Eur. J. Appl. Physiol. 119, 201-211. doi: 10.1007/s00421-0184016-7

Sakaguchi, M., Fukuda, S., Shimada, K., Izumi, Y., Izumiya, Y., Nakamura, Y., et al. (2012). Preliminary observations of passive exercise using whole body periodic acceleration on coronary microcirculation and glucose tolerance in patients with type 2 diabetes. J. Cardiol. 60, 283-287. doi: 10.1016/j.jjcc.2012.05.006

Saquetto, M. B., Pereira, F. F., Queiroz, R. S., da Silva, C. M., Conceicao, C. S., Gomes Neto, M. et al. (2018). Effects of whole-body vibration on muscle strength, bone mineral content and density, and balance and body composition of children and adolescents with down syndrome: a systematic review. Osteoporos. Int. 29, 527-533. doi: 10.1007/s00198-017-4360-1

Sardina, P. D., Martin, J. S., Avery, J. C., and Braith, R. W. (2016a). Enhanced external counterpulsation (EECP) improves biomarkers of glycemic control in patients with non-insulin-dependent type II diabetes mellitus for up to 3 months following treatment. Acta Diabetol. 53, 745-752. doi: 10.1007/s00592016-0866-9

Sardina, P. D., Martin, J. S., Dzieza, W. K., and Braith, R. W. (2016b). Enhanced external counterpulsation (EECP) decreases advanced glycation end products and proinflammatory cytokines in patients with non-insulin-dependent type II diabetes mellitus for up to 6 months following treatment. Acta Diabetol. 53, 753-760. doi: 10.1007/s00592-016-0869-6

Sena, C. M., Pereira, A. M., and Seica, R. (2013). Endothelial dysfunction - a major mediator of diabetic vascular disease. Biochim. Biophys. Acta 1832, 2216-2231. doi: 10.1016/j.bbadis.2013.08.006

Seo, D. Y., Ko, J. R., Jang, J. E., Kim, T. N., Youm, J. B., Kwak, H. B., et al. (2019). Exercise as a potential therapeutic target for diabetic cardiomyopathy: insight into the underlying mechanisms. Int. J. Mol. Sci. 20:6284. doi: 10.3390/ ijms 20246284

Shechter, M., Matetzky, S., Feinberg, M. S., Chouraqui, P., Rotstein, Z., Hod, H. et al. (2003). External counterpulsation therapy improves endothelial function in patients with refractory angina pectoris. J. Am. Coll. Cardiol. 42, 2090-2095. doi: $10.1016 /$ j.jacc.2003.05.013

Shoenberger, R. W. (1972). Human response to whole-body vibration. Percept. Mot. Skills 34, 127-160.

Simon, H. B. (2015). Exercise and health: dose and response, considering both ends of the curve. Am. J. Med. 128, 1171-1177. doi: 10.1016/j.amjmed.2015. 05.012

Singh, R. M., Waqar, T., Howarth, F. C., Adeghate, E., Bidasee, K., Singh, J. et al. (2018). Hyperglycemia-induced cardiac contractile dysfunction in the diabetic heart. Heart Fail Rev. 23, 37-54. doi: 10.1007/s10741-017-9663-y

Solomon, T. P. J. (2018). Sources of Inter-individual variability in the therapeutic response of blood glucose control to exercise in type 2 diabetes: going beyond exercise dose. Front. Physiol. 9:896. doi: 10.3389/fphys.2018.00 896

Sonza, A., Volkel, N., Zaro, M. A., Achaval, M., and Hennig, E. M. (2015). A whole body vibration perception map and associated acceleration loads at the lower leg, hip and head. Med. Eng. Phys. 37, 642-649. doi: 10.1016/j.medengphy.2015. 04.003

Souilhol, C., Serbanovic-Canic, J., Fragiadaki, M., Chico, T. J., Ridger, V., Roddie, H., et al. (2020). Endothelial responses to shear stress in atherosclerosis: a novel role for developmental genes. Nat. Rev. Cardiol. 17, 52-63. doi: 10.1038/ s41569-019-0239-5

Spain, L., Yang, L., Wilkinson, J. M., and McCloskey, E. (2020). Transmission of whole body vibration - comparison of three vibration platforms in healthy subjects. Bone 144:115802. doi: 10.1016/j.bone.2020.115802

Stanford, K. I., and Goodyear, L. J. (2014). Exercise and type 2 diabetes: molecular mechanisms regulating glucose uptake in skeletal muscle. Adv. Physiol. Educ. 38, 308-314. doi: 10.1152/advan.00080.2014

Stefano, G. B., Prevot, V., Cadet, P., and Dardik, I. (2001). Vascular pulsations stimulating nitric oxide release during cyclic exercise may benefit health: a molecular approach (Review). Int. J. Mol. Med. 7, 119-129.

Sturek, M. (2011). Ca2 + regulatory mechanisms of exercise protection against coronary artery disease in metabolic syndrome and diabetes. J. Appl. Physiol. 111, 573-586. doi: 10.1152/japplphysiol.00373.2011

Takase, B., Hattori, H., Tanaka, Y., Uehata, A., Nagata, M., Ishihara, M., et al. (2013). Acute effect of whole-body periodicacceleration on brachial 
flow-mediated vasodilatation assessed by a novel semi-automatic vessel chasing UNEXEF18G system. J. Cardiovasc. Ultrasound 21, 130-136. doi: 10.4250/jcu. 2013.21.3.130

Takeda, Y., Matoba, K., Sekiguchi, K., Nagai, Y., Yokota, T., Utsunomiya, K., et al. (2020). Endothelial Dysfunction in Diabetes. Biomedicines 8, 182.

Tran, V., De Silva, T. M., Sobey, C. G., Lim, K., Drummond, G. R., Vinh, A., et al. (2020). The vascular consequences of metabolic syndrome: rodent models, endothelial dysfunction, and current therapies. Front. Pharmacol. 11:148. doi: 10.3389/fphar.2020.00148

Trigglea, C. R., Dinga, H., Mareia, I., Andersone, T., and Hollenber, M. (2020). Why the endothelium ? The endothelium as a target to reduce diabetes-associated vascular disease. Can. J. Physiol. Pharmacol. 98, 415-430. doi: 10.1139/cjpp2019-0677

Trigiani, L. J., and Hamel, E. (2017). An endothelial link between the benefits of physical exercise in dementia. J. Cereb. Blood Flow Metab. 37, 2649-2664. doi: $10.1177 / 0271678 \times 17714655$

Trinity, J. D., Groot, H. J., Layec, G., Rossman, M. J., Ives, S. J., Morgan, D. E., et al. (2015). Passive leg movement and nitric oxide-mediated vascular function: the impact of age. Am. J. Physiol. Heart Circ. Physiol. 308, H672-H679.

Trinity, J. D., and Richardson, R. S. (2019). Physiological impact and clinical relevance of passive exercise/movement. Sports Med. 49, 1365-1381. doi: 10. 1007/s40279-019-01146-1

Uryash, A., Bassuk, J., Kurlansky, P., Altamirano, F., Lopez, J. R., Adams, J. A. et al. (2015). Antioxidant properties of whole body periodic acceleration (pGz). PLoS One 10:e0131392. doi: 10.1371/journal.pone.0131392

Uryash, A., Wu, H., Bassuk, J., Kurlansky, P., Sackner, M. A., Adams, J. A. et al. (2009). Low-amplitude pulses to the circulation through periodic acceleration induces endothelial-dependent vasodilatation. J. Appl. Physiol. 106, 1840-1847. doi: 10.1152/japplphysiol.91612.2008

Wang, Y. X., Liu, H. B., Li, P. S., Yuan, W. X., Liu, B., Liu, S. T., et al. (2019). ROS and NO dynamics in endothelial cells exposed to exercise-induced wall shear stress. Cell. Mol. Bioeng 12, 107-120. doi: 10.1007/s12195-01800557-w

Wasfy, M. M., and Baggish, A. L. (2016). Exercise dose in clinical practice. Circulation 133, 2297-2313. doi: 10.1161/circulationaha.116.018093

Willey, V., Kong, S., Wu, B., Raval, A., Hobbs, T., Windsheimer, A., et al. (2018). Estimating the real-world cost of diabetes mellitus in the united states during an 8-year period using 2 cost methodologies. Am. Health Drug Benefits 11, 310-318.

Wilson, M. G., Ellison, G. M., and Cable, N. T. (2016). "Basic science behind the cardiovascular benefits of exercise. Br. J. Sports Med. 50, 93-99. doi: 10.1136/ bjsports-2014-306596rep

Womack, C. J., Nagelkirk, P. R., and Coughlin, A. M. (2003). Exercise-induced changes in coagulation and fibrinolysis in healthy populations and patients with cardiovascular disease. Sports Med. 33, 795-807. doi: 10.2165/00007256200333110-00002

Wu, H., Jin, Y., Arias, J., Bassuk, J., Uryash, A., Kurlansky, P., et al. (2009). In vivo upregulation of nitric oxide synthases in healthy rats. Nitric Oxide 21, 63-68. doi: 10.1016/j.niox.2009.05.004

Wu, H., Uryash, A., Bassuk, J., Kurlansky, P., Giridharan, G. A., Shakeri, M., et al. (2012). Mechanisms of periodic acceleration induced endothelial nitric oxide synthase (eNOS) expression and upregulation using an In Vitro human aortic endothelial cell model. Cardiovas. Engin. Technol. 3, 292-301. doi: 10.1007/ s13239-012-0096-4

Wuestefeld, A., Fuermaier, A. B. M., Bernardo-Filho, M., da Cunha de Sá-Caputo, D., Rittweger, J., Schoenau, E., et al. (2020). Towards reporting guidelines of research using whole-body vibration as training or treatment regimen in human subjects-A Delphi consensus study. PLoS One 15:e0235905. doi: 10. 1371/journal.pone.0235905
Xu, L., Chen, X., Cui, M., Ren, C., Yu, H., Gao, W., et al. (2020). The improvement of the shear stress and oscillatory shear index of coronary arteries during enhanced external counterpulsation in patients with coronary heart disease. PLoS One 15:e0230144. doi: 10.1371/journal.pone.0230144

Yanai, H., Adachi, H., Masui, Y., Katsuyama, H., Kawaguchi, A., Hakoshima, M., et al. (2018). Exercise therapy for patients with type 2 diabetes: a narrative review. J. Clin. Med. Res. 10, 365-369. doi: 10.14740/jocmr3382w

Yaribeygi, H., Atkin, S. L., and Sahebkar, A. (2019). A review of the molecular mechanisms of hyperglycemia-induced free radical generation leading to oxidative stress. J. Cell. Physiol. 234, 1300-1312. doi: 10.1002/jcp.27164

Young, W. A., Shaw, D. B., Navach, J., Shizgal, H., and Kowalsky, N. (1965). Effect of CO2 and whole-body vibration on ventilation. J. Appl. Physiol. 20, 844-848. doi: 10.1152/jappl.1965.20.5.844

Yu, M., Tsai, S. F., and Kuo, Y. M. (2017). The therapeutic potential of antiinflammatory exerkines in the treatment of atherosclerosis. Int. J. Mol. Sci. 18:1260. doi: 10.3390/ijms18061260

Zago, M., Capodaglio, P., Ferrario, C., Tarabini, M., and Galli, M. (2018). Wholebody vibration training in obese subjects: a systematic review. PLoS One 13:e0202866. doi: 10.1371/journal.pone.0202866

Zarain-Herzberg, A., Garcia-Rivas, G., and Estrada-Aviles, R. (2014). Regulation of SERCA pumps expression in diabetes. Cell. Calcium 56, 302-310. doi: 10.1016/j.ceca.2014.09.005

Zhang, J., and Friedman, M. H. (2012). Adaptive response of vascular endothelial cells to an acute increase in shear stress magnitude. Am. J. Physiol. Heart Circ. Physiol. 302, H983-H991.

Zhang, J., and Friedman, M. H. (2013). Adaptive response of vascular endothelial cells to an acute increase in shear stress frequency. Am. J. Physiol. Heart Circ. Physiol. 305, H894-H902.

Zhang, Y., He, X., Liu, D., Wu, G., Chen, X., Ma, H., et al. (2010). Enhanced external counterpulsation attenuates atherosclerosis progression through modulation of proinflammatory signal pathway. Arterioscler. Thromb. Vasc. Biol. 30, 773-780. doi: 10.1161/atvbaha.109.197806

Zheng, Z. S., Yu, L. Q., Cai, S. R., Kambic, H., Li, T. M., Ma, H., et al. (1984). New sequential external counterpulsation for the treatment of acute myocardial infarction. Artif. Organs. 8, 470-477. doi: 10.1111/j.1525-1594.1984.tb04323.x

Zhou, J., Li, Y. S., and Chien, S. (2014). Shear stress-initiated signaling and its regulation of endothelial function. Arterioscler Thromb Vasc. Biol. 34, 21912198. doi: 10.1161/atvbaha.114.303422

Zhou, Z., and Griffin, M. J. (2014). Response of the seated human body to wholebody vertical vibration: discomfort caused by sinusoidal vibration. Ergonomics 57, 714-732. doi: 10.1080/00140139.2014.898799

Ziolo, M. T., Kohr, M. J., and Wang, H. (2008). Nitric oxide signaling and the regulation of myocardial function. J. Mol. Cell. Cardiol. 45, 625-632. doi: 10.1016/j.yjmcc.2008.07.015

Conflict of Interest: MS and JA draw no salary from Sackner Wellness Products LLC a company which has a patent on a passive jogging device. MS owns $80 \%$ and JA $20 \%$ of the domestic and foreign patents.

The remaining authors declare that the research was conducted in the absence of any commercial or financial relationships that could be construed as a potential conflict of interest.

Copyright (c) 2021 Adams, Uryash, Lopez and Sackner. This is an open-access article distributed under the terms of the Creative Commons Attribution License (CC BY). The use, distribution or reproduction in other forums is permitted, provided the original author(s) and the copyright owner(s) are credited and that the original publication in this journal is cited, in accordance with accepted academic practice. No use, distribution or reproduction is permitted which does not comply with these terms. 